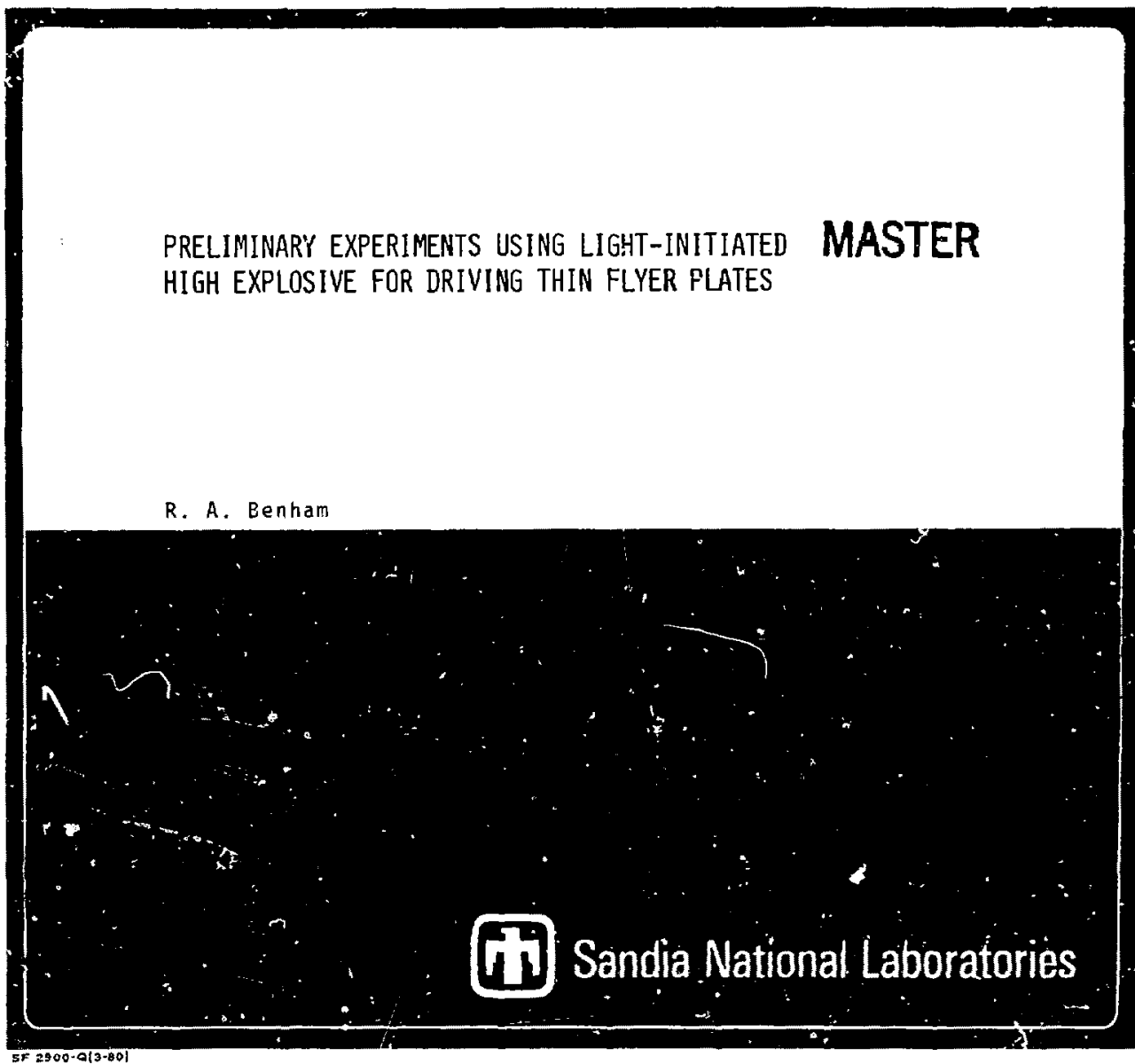




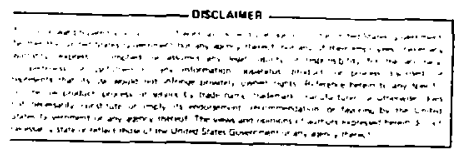

Printed in the United States of America

Available from:

National Technical Information Service

U. S. Department of Commerce

5285 Port Royal Road

Springfield, Virginia 22161

price: Printed Copy $\$ \theta$; Microfiche $\$ 3.60$

$A<3 \quad A \circ 1$


PRELIMINARY EXPERIMENTS USING LIGHT-INITIATED HIGH EXPLOSIVE FOR DRIVING THIN FLYER PLATES*

\author{
R. A. Benham \\ Explosives Testing Organization 1533 \\ Sandia Laboratories \\ Albuquerque, New Mexico 87185
}

January 1980

\begin{abstract}
Light-initiated high explosive, silver acelytide--silvernitrate ( $S A S N$ ), has been used to produce simulated $x$-ray blowoff impulse loading on reentry vehicles to study the system structural response. SASN can be used to accelerate thin flyer plates to high termiril velocities which, in turn, can deliver a pressure pulse that can be tailored to the target material. This process is important for impulse tests where both structural and material response is desired. This report summarizes the theories used to calculate the dynainic state of the flyer plate prior to impact. Data from several experiments are presented which indicate that thin flyer plates can be properly accelerated and that there are predictive techniques availatie which are adequate to calculate the motion of the flyer plate. Recommendations are made for future study that mus: be undertaken to make the SASN flyer plate technique usable.
\end{abstract}

Key Words: impulse testing, pressure pulse shaping, $x$-ray blowoff simulation

\footnotetext{
This work was supported by the United States

Department of Energy (DoF).
} 
CONTLNTS

INTRODUCTION

Page

TBCHNJQUE

1

THEORY

3

EXPERIMLNTAL EVIDENCE

RI:SULTS

CONCLUSIONS AND RECOMMI:NDATIONS ?

ACKNOHLEDGMENT I0

REFI:RENCLS 


\section{LIST OF FICURES}

$\underline{\text { Page }}$

Figure 1. Explosive Configuration 13

Figure 2. Sketch of Experimental Setup 14

ligure 3. Experimental Setup 15

Figure 4. Assembled Test Fixture 16

Figure 5. Flash X-ray Setup 17

Figure 6. Test Assembly in Front of Light Array 18

Figure 7. Flash X-ray Data from Tes: 11

Figure 8. Flash $X$-ray Data from Test * 2

Figure 9. Fiash X-ray Data from Test \#3 21

Figure 10. Flash X-ray Data from Test $\# 4$

Figure 11. Fost-Impact Flyer, Explosive Side 23

Figure 12. Post-Impact Flyer, Impact Side 24

Figure 13. Profile of Flyer Plate After Cushion
Frfect has Caused Rebound

Figurc 14. Predicted Motion of Flyer 26

Figure 15. Predicted Pressure Developed at the
Farset Surface

Figure 16. Comparison Between Prediction and
Measurement for Test $\# 2$

TABLES

Table 1. Effec: of Fxpansion Exponent $n$ on Flyes Motion 6

Table 2. Flyer Plate Experimental Results 12 
PRELIMINARY EXPERIMENTS USING LIGHT-INITIATED

HIGH EXPLOSIVE FOR DRIVING THIN FLYER PLATES

\section{Introduction}

Light-initiated high explosive has been used to produce impulse loads on various structural menbers including larg,c complex structural systems. Surface areas up to one square metre have been subjected to a simultaneously-applied, distributed impulse load both with and without load discontinuities. The dynamic loading, which is intended to simulate $x$-ray induced blawoff impulse, has been designed to produce structural lesponse. * In a nuclear encounter, both raterial and structural response result when the surface material of the structure vaporizes and is blown off. In the past, no at tempt has been made to tailor the pressure pulse from the light sensitive explosive for investigation of combined structural and material response. The light-initiated high explosive (LIHE) technique would be enhanced as a simulation tool if pressure tailoring could be added to ics capabilities.

Fressure tailoring has been accomplished in other impulse simulation techniques by drivirg thin flyer plates to infact the surface of the test structure. ${ }^{1,2}$ The mechanics of pressure tailoring of the plate impact pressure pulse are the same regarcless of the method of driving the flyer plate. Earlier work ${ }^{3}$ has indicated that LIHE can accelerate flyer plates to velocities high enough to produce peak pressure loading of tens of kilobars in typical weapon structure materials.

\footnotetext{
A load appears impulsive to a structure if the pressure duration is short compared to the shortest structural response pericd of the test item.
} 
Also, a preliminary set of experiments has been conducted at Southwest Research Institute" which has proven the feasibility of acceleratisg thin flyer plates (both electrical conductors and nonconductors) with spray-deposited, lightsensitive explosive.

This report summarizes the theories used to calculate the Bynamic state of the flyer plate prior to impact. The shock wave mechanics used to predict the actual pressure input to the test surface are not discussed here since the topic is covered in detail elsewhere." 2,5 A set of experiments that was conducted at Sandia Laboratories to further investigate the use of $]$ ight-sensitive explosive to accelerate thin plates is discussed. The most recent explosive formulation and handling techniques were used. The objectives of the experiments nere: (1) to reverify experimentally that thin flyer plates could be accelerated to terminal velocity while retaining the $f$,oper flatness and orientation; and (2) to evaluate existing explosive hehavior theories and flyer plate gap transit theories for predicting the actual behavior during travel to impact. These abjectives must be successfully met to allow the design of complex simulation experiments on real structures. The data from thase experiments is presented which indicate that thin flyer plates can be properly accelerated and that the predictive techniques are adequate to calculate the motion of the flyer plate. Recommendations are made for future study that must be undertaken to make the LJHE technique experimentally usable.

\section{Technique}

The process for this technique starts with the careful formulation of the explosive in the form of a slurry. The explosive is then sprayed onto the test structure, the mass distribution over the surface being controlled by using various combinations of masks and/or overlapping spray passes. The explosive distribution is evaluated using local explosive vight 
measurements and/or beta backscatter areal density measurements during the spraying operation. The test item is then remotely transported to the test site and positioned in front of a capacitor discharge light source. An intense fiash of light

initiates the explosive and the resulting gas expansion produces a pressure load on the test structure surface.

In the proposed pressure tailoring experiments, the sprayed structure is a thin flyer plate. The plate is accelerated tc a terminal velocity by the pressure pulse from the expanding gas of the explosive detonation. The flyer travels through a gap to impact the test structure. The pressure loading to the structural surface depends on the material and impact velocity of the flyer, on the nature of the air cushion effect, and the material of the test structure. ${ }^{1-4}$

\section{Theory}

The phenomena that are considered for calculation of the flyer plate motion are: initiation of a known quantity of explosive, expansion of the explosive products, and compression of the ambient gas between the flyer plate and the target. The important parameters to be calculated are the time of arrival and velocity of the plate at impact. In some cases, the compressed gas between the flyer and target may siove enough energy to actually reverse the travel of the flyer plate producing a smooth, nearly-symmetrical pressure pulse in the target. The total momentum delivered to the test surface is dependent on the total change in velocity of the flyer plate, so the rebound condition must be understood. It is the intent of this paper to predict the motion of the flyer plate prior to impact.

For the analysis, it is assumed that the explosive is uni folmly initiated by instantly converting the solid explosive mass to the same volume and density of high pressure gas, and that detonation propagation direction has little effect on the 
process. The explosive products are assumed to expand uniformly with a linear velocity profile across the thickness of the explosive/explosive gas. The pressure at the interface between the explosive products and the flyer plate drives the flyer to the terminal velocity. The terminal velocity magnitude can be determined using the Gurney ${ }^{6}$ approach. The velocity is a function of the Gurney velocity $(\sqrt{2 \mathrm{E}}){ }^{*}$ and the areal density of the explosive (C) and of the flyer (M). Equation 1 shows this relationship." Figure 1 is a sketch of the explosive system showing the geometry and terminology of the Gurney solution.

$$
v_{\text {terminal }}=\sqrt{2 \mathrm{E}}\left[\frac{\left(1+\frac{2 \mathrm{~A}}{\mathrm{C}}\right)^{3}+1}{\sigma\left(1+\frac{1}{\mathrm{C}}\right)}+\frac{\mathrm{M}}{\mathrm{C}}\right]^{-1 / 2}
$$

This terminal velocity is reached at the end of the explosive push or acceleration phase of the plate motion when the cxplosive products' pressure has been reduced to near ambient).

The Gurney velocity, $\sqrt{2 \mathrm{E}}$, for the light sensitive explosive is found experimentally by measuring the impulse delivered to a rigid Wil (i.e. $M / C 71$ ). Using equation $I$ wit? $M / C, 71$ and defining the rigid wall impulse as the mass of the flyer times the terminal velocity the following is obtained.

$$
\sqrt{2 E}=\frac{I_{\text {rigid wal1 }}}{C} \sqrt{\frac{4}{3}}
$$

A calibration curve relatang the impulse and the explosive areal density has been determined for ilHE." The combination of the calibration curve and equation (2) leads to a description of $\sqrt{2 E}$ as a function of explosive areal density, $C .7$

The time required to reach the terminal velocity can be calculated using the polytropic expansion process $\mathrm{PV}^{\mathrm{n}}=$ constant

"The Gurney velocity is a property of the explosive which indicates ،ire effectiveness of the expiosive in propelling material. 
fer the gas and $P A=M \ddot{X}$ for the flyer. A is the area over which the pressure acts, $M$ is the mass of the flyer, $\ddot{X}$ is the acceleration of the flyer and $n$ is the expansion process exponent. The value of $n$ is to be discussed later.

Integrating this equation twice and putting ja the values for the initial condition gives the expression ( 3 ) for time, $t$, as a function of position, $x$.

$$
t=\left[\frac{(n-1) M}{2 p_{0} x_{0}^{n}}\right]^{1 / 2} \int_{x \circ}^{x} \frac{d x}{\left(\frac{1}{x_{0}^{n-1}}-\frac{1}{x^{n-1}}\right)^{1 / 2}}
$$

$P_{0}, x_{0}, g, N$ are initial pressure, initial explosive half thich ness, gravity constant, and flyer arcal density respectivel, The flyer terminal velociôy can be determined from this approach and is $V_{\text {term }}=\frac{2 \mathrm{P}_{0} \mathrm{X}_{0} \mathrm{~g}}{(\mathrm{n}-1) \mathrm{N}} \cdot{ }^{8}$ Using equation (3), one can determine the. time for the flyer to reach position $x$ by integrating rrom the starting position, $x_{0}$, to position $x$. The value $x_{0}$ is the distance between the flyer plate surface and the plane in the explosive of zero particle motion ffrom the assumption of a lincar velocit profile of the explosive debris). This reference plane occurs at different locations within the thickness of the cxplosive depending upon the exact confjguration. For the open face sandwich configuration under consideration here, $x_{0}$ can be foum from

$$
\frac{T-x_{0}}{x_{0}}=1+2 \mathrm{~N} / \mathrm{C},
$$

where $T$ is the explosive thickness (see Figure 1).

A sensitivity study of the effect of charging the exponent $n$ on the flyer transit time through the ga! has been conducted. Table 1 shows a small part of this study. 
TABLI: 1. LFIECT OF LXPANSION EXPONENT $\mathrm{n}$ ON FLYLK MOTION

\begin{tabular}{|c|c|c|c|c|c|}
\hline$n$ & Gap & $\begin{array}{c}\text { Flyer } \\
\text { Areal } \\
\text { Density } \\
\text { (M) } \\
\end{array}$ & $\begin{array}{c}\text { Explosive } \\
\text { Areal } \\
\text { Density } \\
\text { (C) } \\
\end{array}$ & $\begin{array}{l}\text { Cap } \\
\text { Transit } \\
\text { Time }\end{array}$ & $\begin{array}{c}\% \text { of Maximum } \\
\text { Flyer } \\
\text { Momentum at } \\
\text { Impact }\end{array}$ \\
\hline 1.4 & $.057 \mathrm{~cm}$ & $.089 \mathrm{gm} / \mathrm{cm}^{2}$ & $.020 \mathrm{gm} / \mathrm{cm}^{2}$ & $7.25 \mu \mathrm{sec}$ & 83.6 \\
\hline$\hat{i}$ & $.057 \mathrm{~cm}$ & $.089 \mathrm{gra} / \mathrm{cm}^{2}$ & $.020 \mathrm{gm} / \mathrm{cm}^{2}$ & $5.354 \mathrm{sec}$ & 49.6 \\
\hline
\end{tabular}

Transient time through gap for constant velocity $=5.16 \mu \mathrm{scc}$

The flyer is assumed to be traveling in

a vacuum.

Maximum flyer momentum $=987$ tans

(terminal flyer velocity of $11036 \mathrm{~cm} / \mathrm{sec}$ ).

If $n$ is low, chen the acceleration time is long. Terminal velocity was not reachej at impact for $n=1.4$ of lablc I. $n$ is high, then the energy from the expanding gas is delivered to the plate in a much shorter distance resultin: in higher accelerations.

Since simultaneity of loading is important. Experiments are currently underway at Sandia to evaluate the explosive expansion process.

The flyer plate must travel throush a finite gap belore impacting the test surface. Air, is any, hetween the rlyer and test surface compresses to form a cushion prior to plate inpact. This cushion effect will minimally cause a smooth pressure precursor prior to impact shock delivery or maximally cause the flyer to reverse direction without actually impacting the test surface (a symmetrical pressure pulse with double the rlyer plate momentum being delivered). The air cushion effect has received considerable attention $3,2,4,5$; therefore the thoory will not be described here.

The ideal experimental condition for flyer plate inpt lsc delivery is to have the flyer plate reach terminal velocicy before the gap has been trazersed so that there is not a gradicnt 
in flycr velocity as a function of distance in the regton of the impact. Ideall $\%$, the cushion effect should not be ar..... $\left.a^{b}\right] \mathrm{e}$ during the acceleration phase of the transit. thus allowing decoupling of the accelcration calculations from the cushion cial. culations.

in the first attempt at callulating the ilyes transit a: a gap, the flyer was assumed to he at ihe terminal velocity after havine traveled sone specified Jistance acros: the pap. He alt cushion equations were then used to predict the continuation of the flyer on to innat or rebound. A computer proprals based on the previously cited work has heen written bhich predicts the motion of the, ajr cushioned, driven flyeg plate. I relint ment to this method includes aldeulation of the motion nf the flyer through the acceleration phasc."

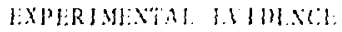

A series of four experinen:s was conducted in tune lat-to provice data for accessing the utility of the tebnifue 1 : min purposes vere:

i) Verify that a thin $(.43 .3$ anthich aluminum flyer plate can be accelerated ir a plane, uniformianmer.

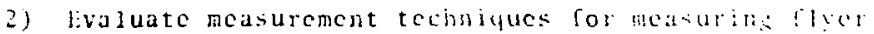
plate condition and displaccment history.

3) Livluate predictive techniques ol terminal tlur lelocity and air cushion eflect.

The data collected to achuec the above listed puposes were: 1) the physical condition of the post test flyer:

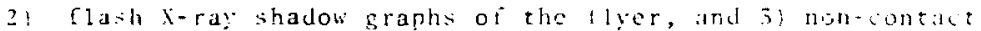
ing (eddy current) displacement sage measurements.

The experimental setup consisted of a . $1.3 \mathrm{sen}$ thich aluminum flyer plate $7.6 \mathrm{~cm}$ in diameter that wat attalied to a thenolic suppo:t ring by means of a layer of paper stretcined across the diameter o: the ring. The phenolic ring was posi tioned in a gage hol ling fixture. Jigure 2 shows a crosssection of the test setup and ligure $j$ shows a photograph $n$ 
the actual hardware. Jetonation timing crystals were attached to the holder for determination of time initiation (Figure 4). The explosive on the outside of the assembly (see igure 2) was initiated, by the flash of light from a capacitor bank discharge," 0 thus driving the flyer plate through the gap toward the displacement gage. A gap between the flyer and the gage of $1.27 \mathrm{~cm}$ was chasen to allow measurement of flyer motion after the clectrical system recovered from the capacitor bank noise bluck out and to alow sufficient travel for obtaining flash $x$-ray exposures of the flycr plate during transit. Flash $X$-ray exposures were taken as the flyer traveled through the gap to show flyer velocity and conIition at various times after initiation. Higure 5 shows the flash $x$-ay setup and Figure 6 shows the tast assembly in front of the light soirce. ?ise output from the displacement gage was recorded on an oscilloscope for the first test and on a disc recorder with 1 Mliz frequency response for the second and third test. The detonation timing crystal signals were also recorded on an oscilioscope.

\section{RESULTS}

Figures 7 through 10 show reproduction of the flash X-ray data. Table 2 is a summary of the test data. Figures 11 and 12 show the llyers after the test. "?he large buckles were caused when the flyer rebounded out of the ausembly and impacted tire lighe array.

After each of tine first three tests, it was noticed that the rebound of the flyer was lower than expected, so the fourth test was cordicted with only the $x$-ray to verify that the edges of the flyer were impacting the fixture while over the gage the compressed air did not allow inpact. See Figure 13. Figure 10 shows the $x$-ray of the rebounded flyer plate.

The flatness of the flyer plate in Figures 7,8 , and 9 is sufficient for impazt experiments. In actual experiments, transit gaps will be held to less than .254 cm so that flatness and tilt will be typically better than shown in the fjrst exposure. 
The displacement gage was susceptible to electrical noise, as rantioned above, and so was saturated by the electrical noise of the capacitor bani light source for early times. The initiation timing crystals were used to determine the stari of flyer motion. Final flyer velocity and air cushion effect could be rusily determined using the displacement gages.

The most complete displacement data was obtained from the sccond test. The explcsive initiation time was delayid tinc longest, causing the signal to start later in the noise blackout time. inigures 14 and 15 show the predicted motion history and pressure at the target face using the obovermentioned model and computer program.* Figure lo shows the comparison beswer. the prediction and measurement for test $\dot{F} 2$. Agreement is good up to the point of maximum gas compression. lige re'ief of the comprosiod has caused the edges to be retarded less than the conter and impact the gage holder causing energy to leave the fyyer and therefore rebe and at a lower than expected velocity.

\section{CONCLUSIONS AND RECOMGENDATIONS}

At least one class of Elyer plates (.033 cm thick aluminum) can be accelerated with spray deposited light HE with surficiont planarity aná predictability to be used in pressurc pulse tililoring impulse experiments. Impact conditions (velocity, tincl ciat bc predicted fairly well with existing approximations to the fias expansion process. Design of a complex experiment will require better understanding of the explosive behavior. A better resolution transducer (fibre optics, capacitance gages) should bo used to observe the acceleration history of a flyer piate to define the explosive cxpansion process to a better degrec.*x

\footnotetext{
${ }^{*}$ The computer program listing is not included in this report but is available Erom Division J533.

* The cxperimental work and an analytical model have been accom plished and are soon to be published.
} 
experiments on flat configurations shouli be conducted to verify tailozed pressure shape and amplitude for both contact and cushioned experiments. Pressurc transducer terhnology will currencly allow this investigation. Fixperiments to extend the range of impulsc levels should be conducted. Wethods of physicil support of the flyer for full system experiments must he derel cped, as well as a program to usc the calculational elenent of this report to design a complete system load with impulse, pres. sule and simulancity contralled.

\section{KKNOWHIUGN1.XI}

The author would ljke to express appreciation to ll. I.. Shires who conlucted the explosive experiments, to k. H. Huggins who provided the displacoment measuring schome and assisted in con. puter programming, to $P$. B. Higgins who assistod with inst rument. at ion and facility operation, to lialter till for his comncas tan this report and to Anna sasic tartoll for preparing the text 


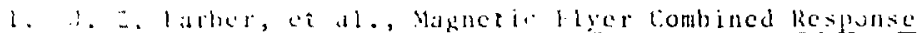

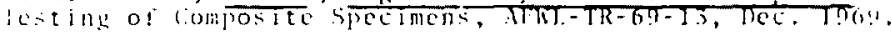

$\therefore \quad$ V. K. Burnhaum, ot al., lmualse llelirered to largets in

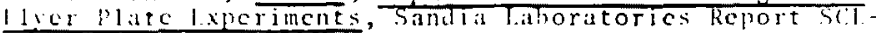

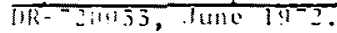

$\vec{s}$. Vemorandum o! Record: Suhject, "I.ight-lnitiated lexplosire

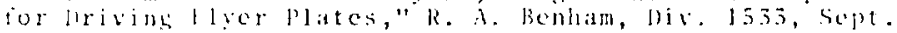
$1: 2^{-\cdots}$.

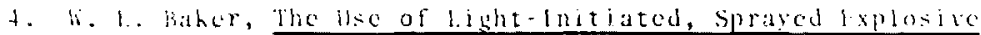
to iccolerate Ther Tates, Techical Report Tumber ThT? -

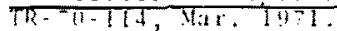

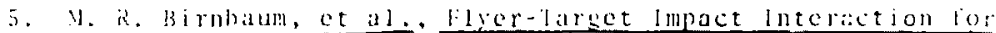

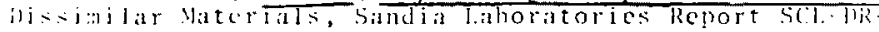

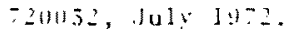

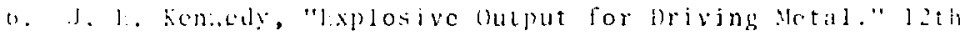
hnual Syaposium AStll. Rehavior and tlt ilization of

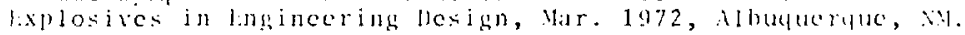

$\because$ Vemoriandum of Record: Suhject, "Gurncy l'clocity Cor l.ikhi" Initiated lligh lxplosive,"R. A. Benhan, Div. 153.3, Sept. $13^{-\cdots}$.

b. incin fi. Honry, The liurney formula and Related luproximat ion for the lligh-lixplosive leplovment of Fragments, Hughes dir ina! Company Report lo, PUB-189, ए. 36, :pril 196:.

?. R. 1. Renham, In Initiation and las Fxpansion Hodel for the Light-Initiated Explosive Silver fectylde-Silver Nitrate, Sandia laboratorics keport No. SnND79-1829, Jan. 1980.

10. H. H. Higgins, "An Are Source for lnitiating light-sensitivo f.xulosive," Shock \& libration Bulletin, Part 5, pp. 191-195, iugust 1970 . 


\begin{tabular}{|c|c|c|c|c|c|c|c|c|c|}
\hline \multirow[b]{2}{*}{$T e s t$} & \multirow{2}{*}{$\begin{array}{c}\text { Explosive } \\
\text { Area! } \\
\text { Density } \\
\text { (4r/cm } \\
\text { (c) }\end{array}$} & \multirow{2}{*}{$\begin{array}{c}\text { Explosive } \\
\text { Initiation } \\
\text { Tilne } \\
\text { (Crystais) } \\
\text { usec }\end{array}$} & \multirow{2}{*}{$\begin{array}{c}\text { Erecetive } \\
\because \text { yes } \\
\text { धpickness } \\
\text { cm }\end{array}$} & \multirow{2}{*}{ 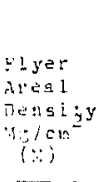 } & \multirow{2}{*}{ 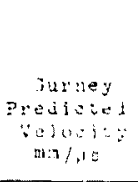 } & \multicolumn{2}{|c|}{ 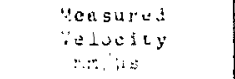 } & \multirow[b]{2}{*}{$\dddot{Z 2: 1}: n n^{\prime} \leq s$} & \multirow[b]{2}{*}{ 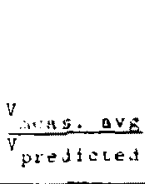 } \\
\hline & & & & & & 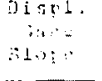 & 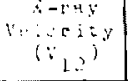 & & \\
\hline 1 & $.0 .217+5 \%$ & $42^{[1]}$ & .0300 & .099 & $.111: 0$ & $-\lfloor\vdots$ & 12100 & 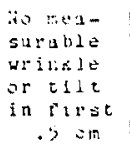 & 1.080 \\
\hline 2 & $.0225 \pm 57$ & 53 & .0370 & .1019 & .11372 & .12999 & .11905 & $"$ & $1.0 ; 1$ \\
\hline 3 & $.0225 \pm 57$ & 38.5 & .0373 & .1012 & .11440 & $-\lfloor 2\rfloor$ & .21723 & $"$ & 1.025 \\
\hline $4^{[4]}$ & $.0206 \pm 5 \%$ & $31,32,34$ & .0306 & .100 & $.1030^{a} u$ & $-[3]$ & .11293 & $n$ & 1.087 \\
\hline
\end{tabular}

[1] Explosive initiation is controlled by listance betreen the explosive surface and the light source

(2) Initial slope dicricult co mesure because the explosive initiated turingejecticil "Djhokout" time from light source apgeidor disciariti

[3] ido displacement gages usea

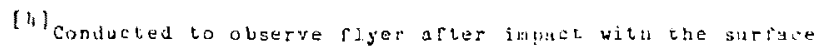

TABLE 2, FLYER PLATE EXPERIMENTAL RESULTS 


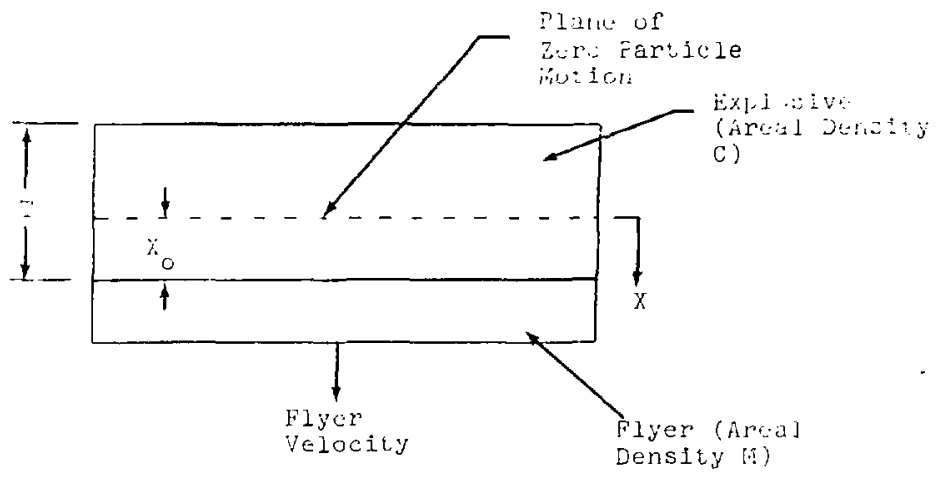

FIGURE 1. EXPEOS IVE CONFIGURATION 


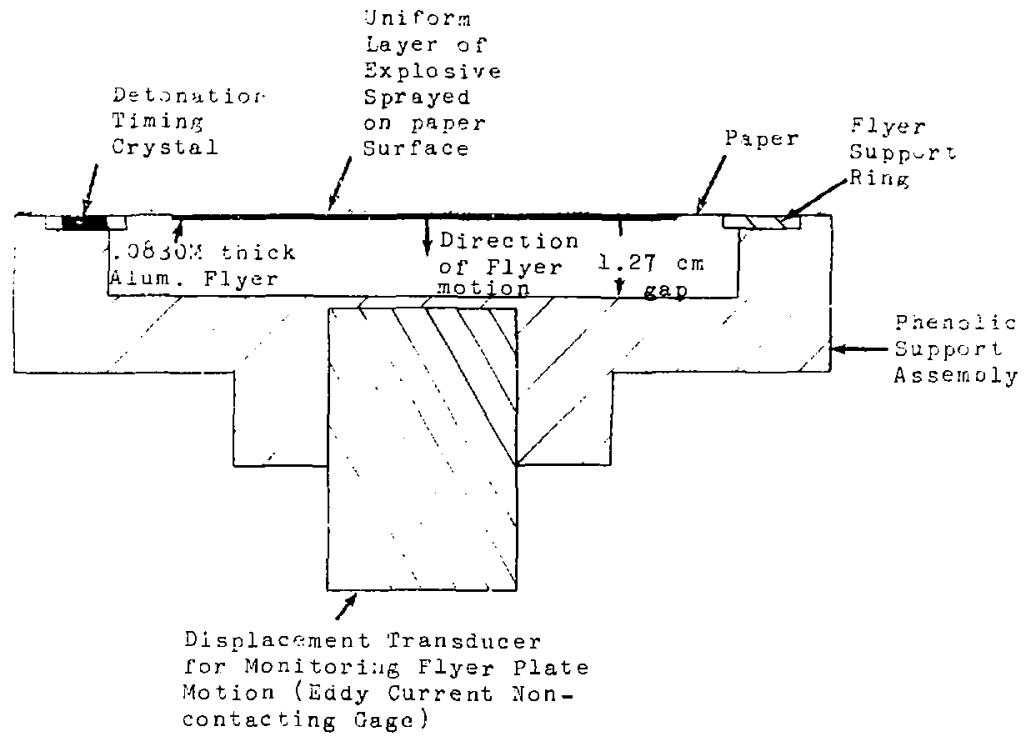

FI UURE 2. SKETCH OF EXPERIMENTAL SETUP 


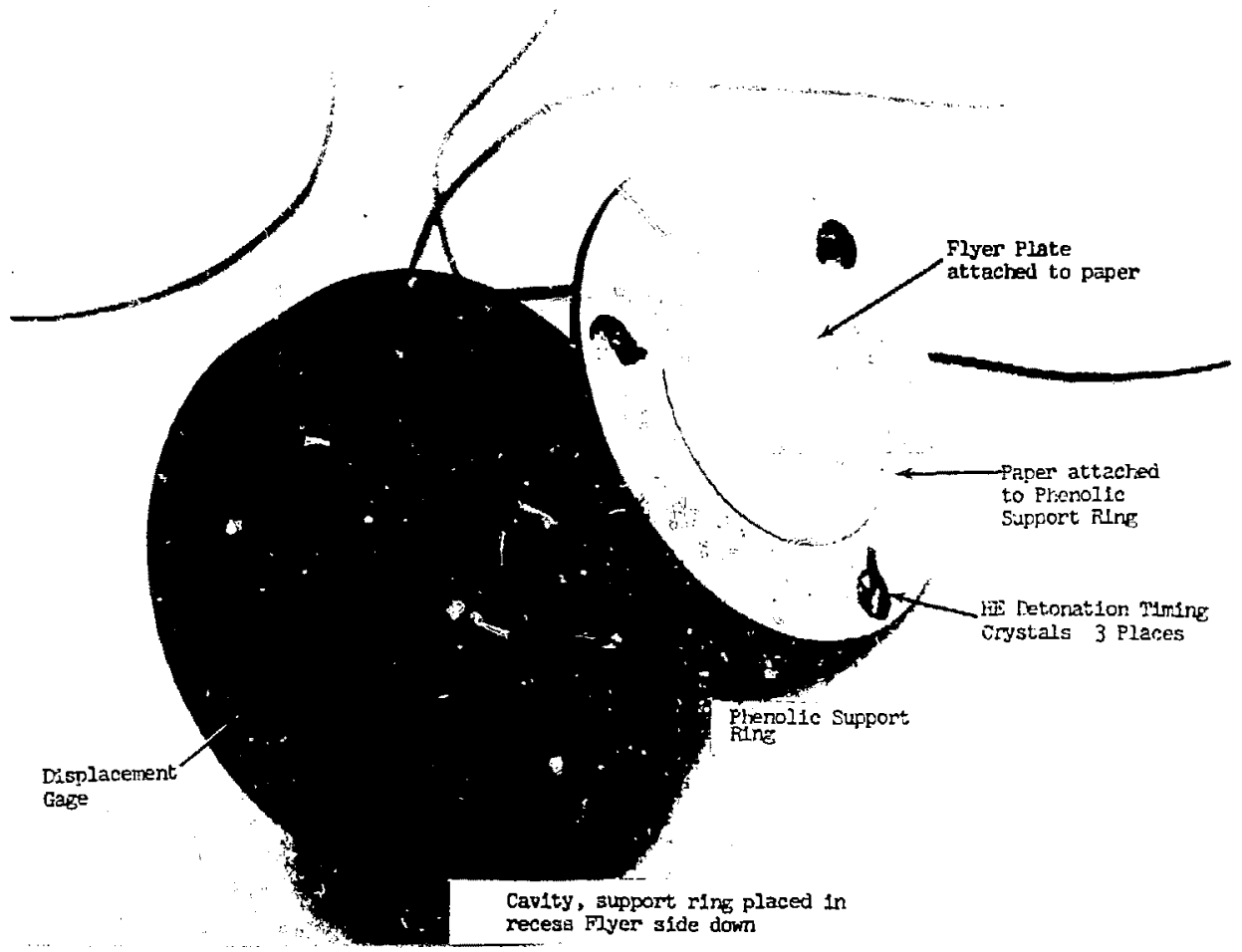

FIGURE 3. EXPERIMENTAL SETUP 
D77-10093

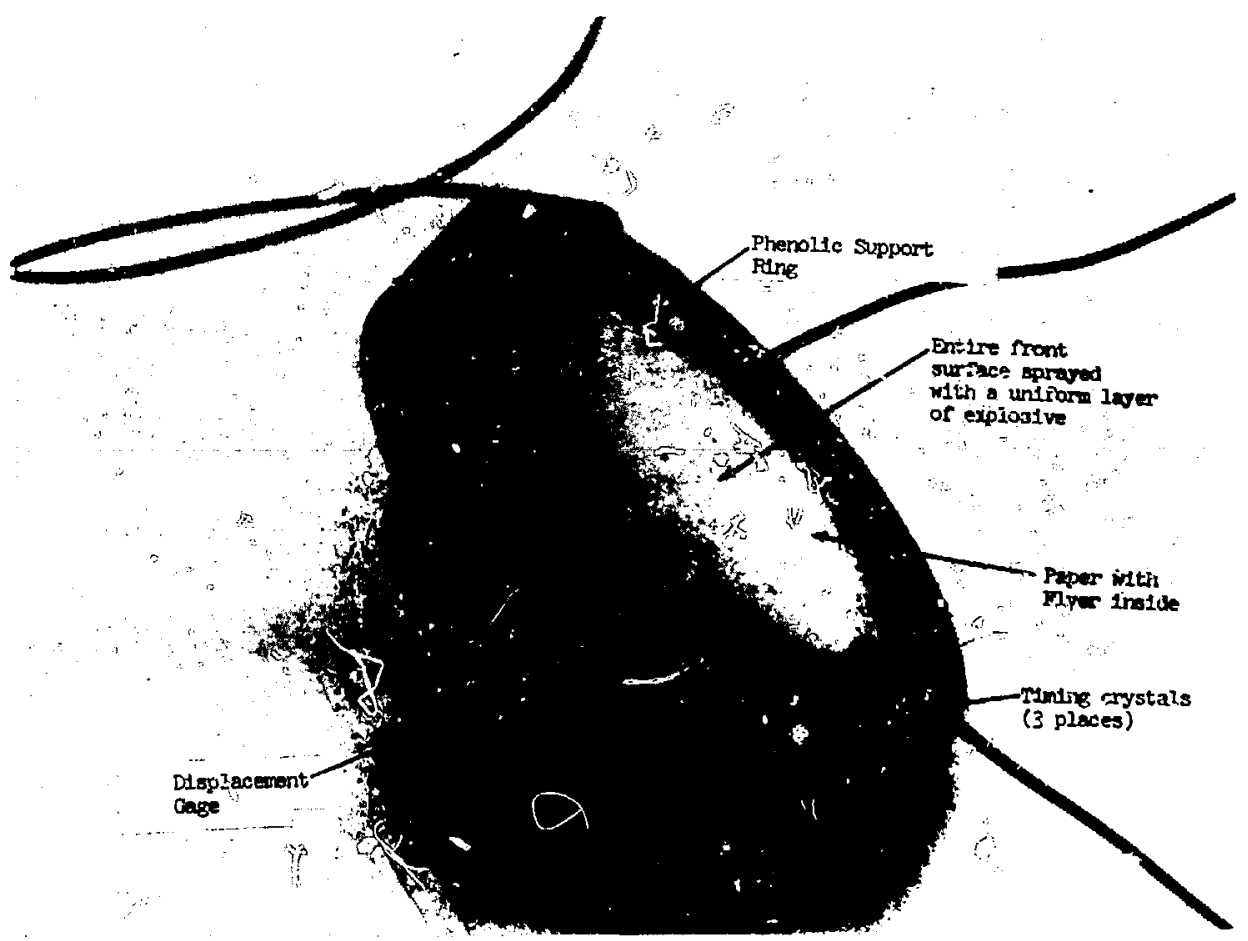




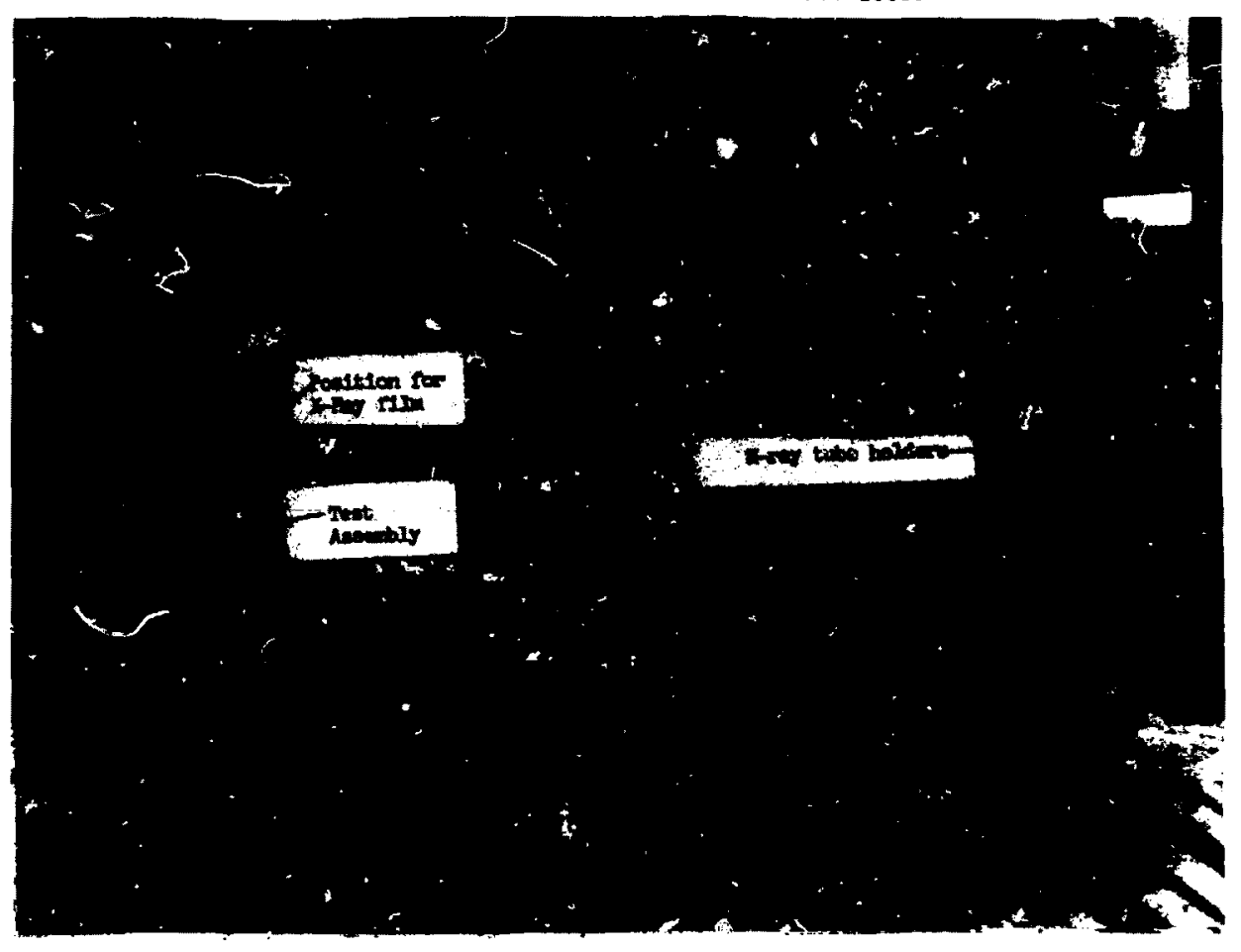




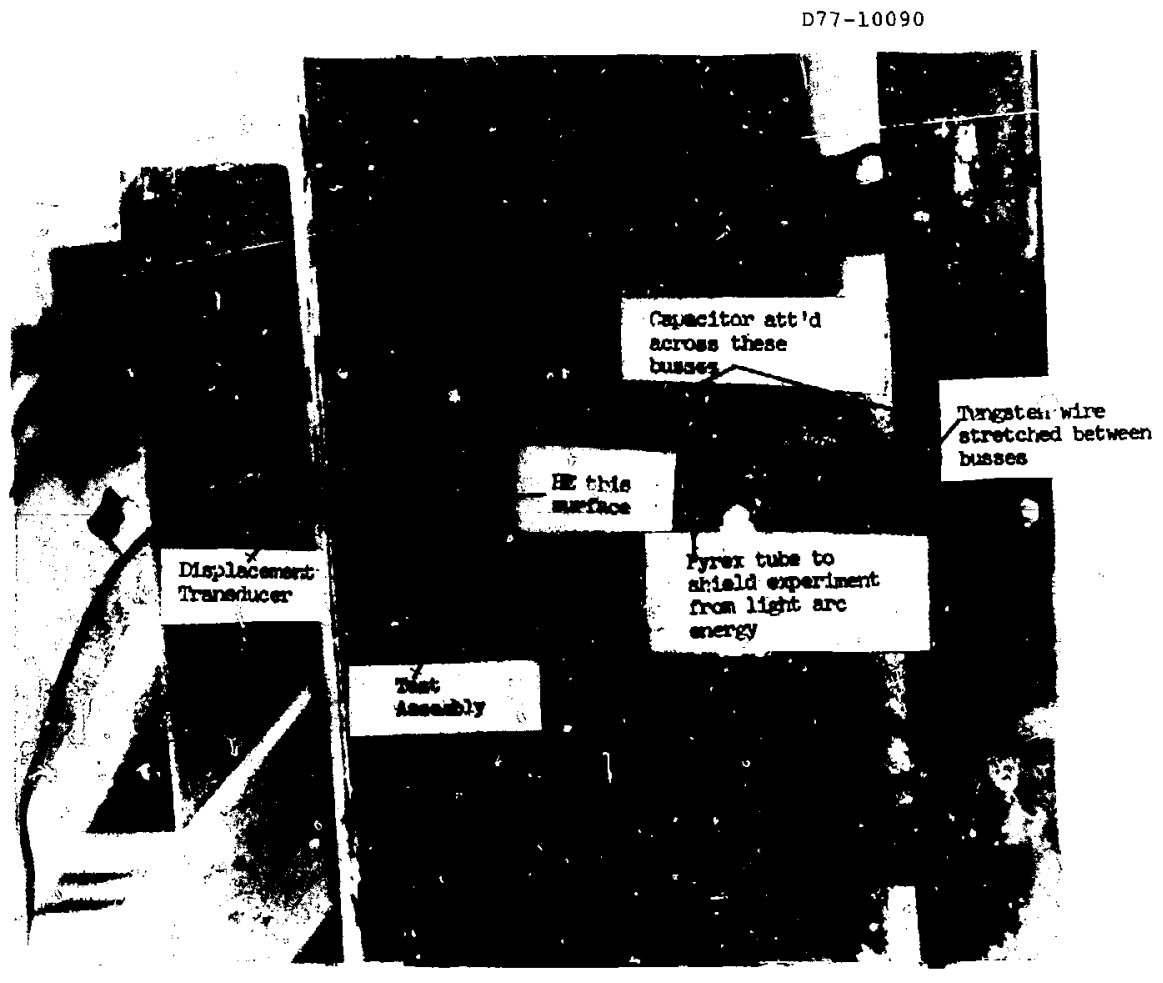




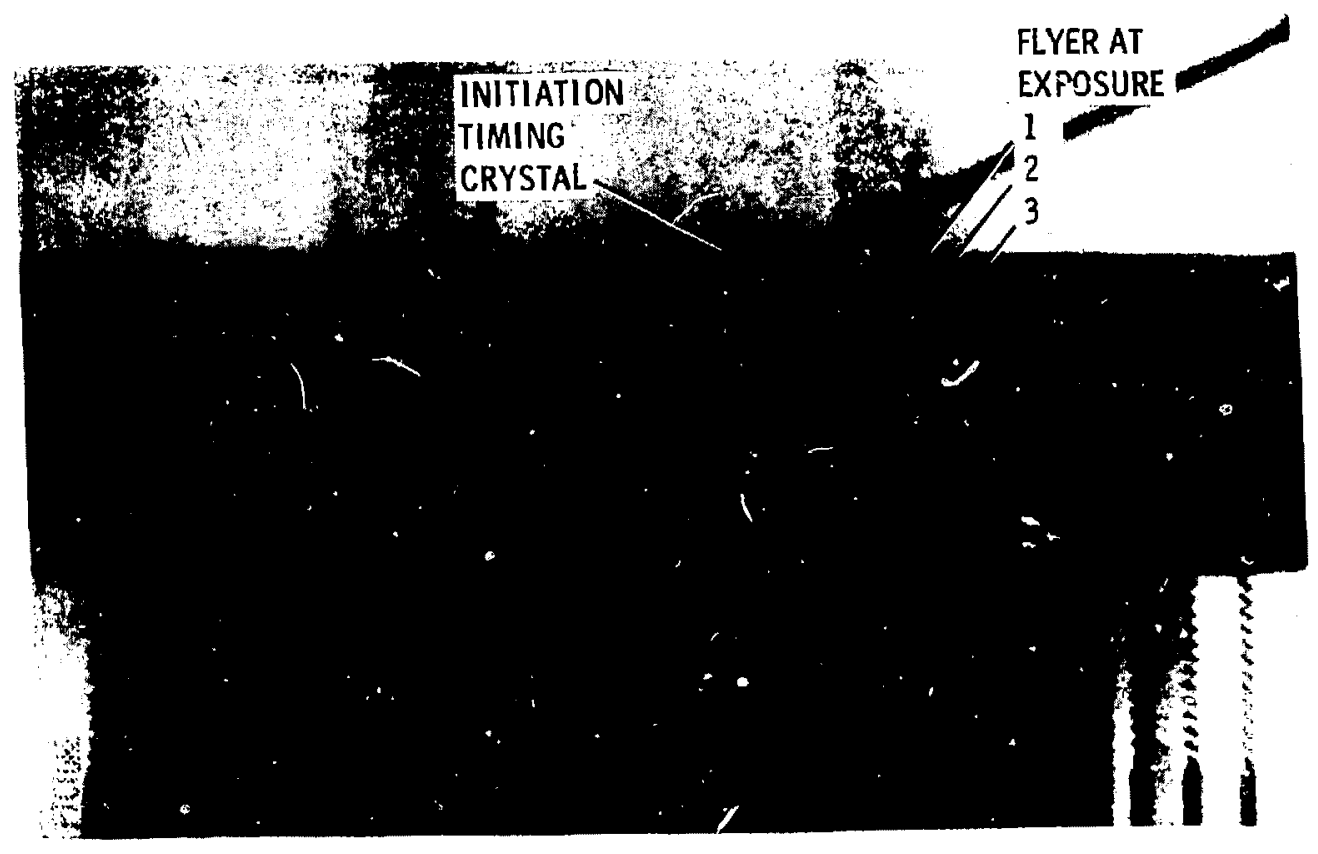




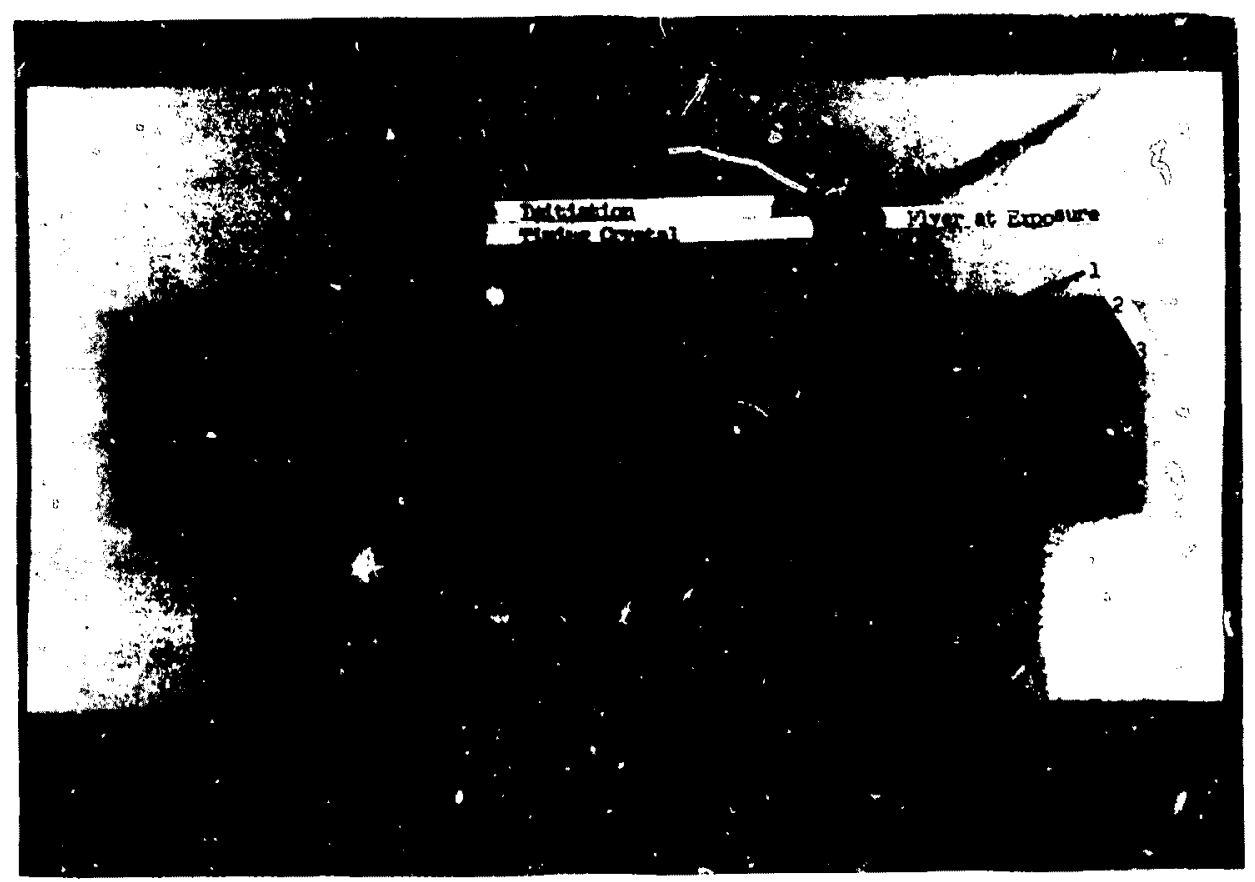




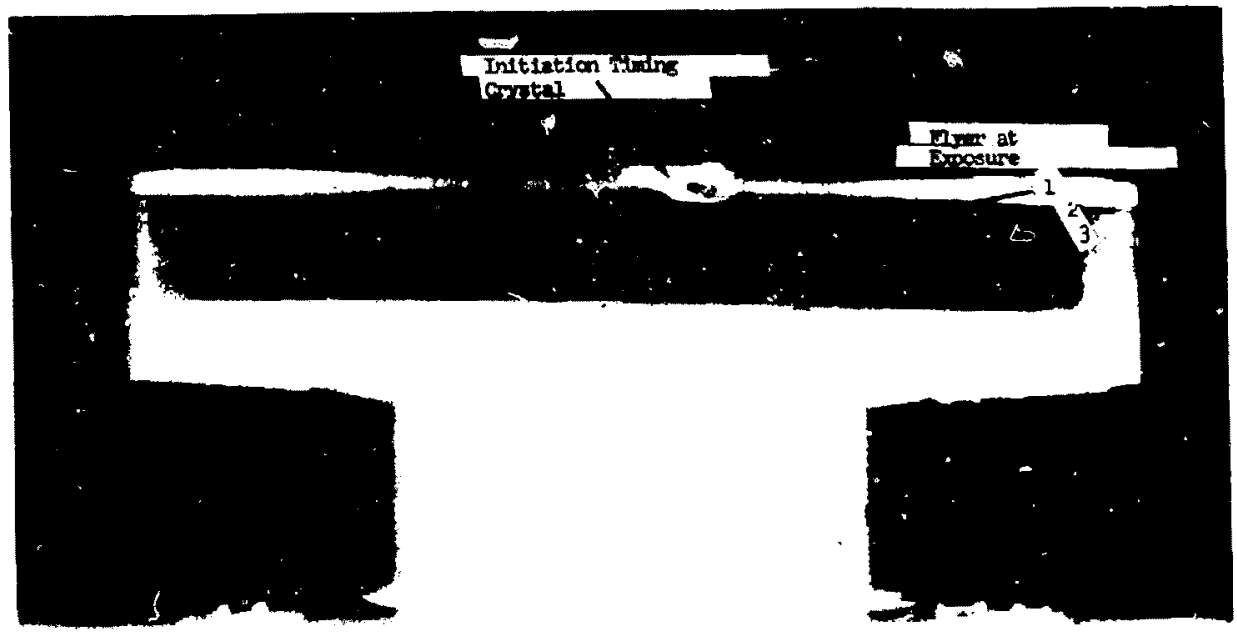




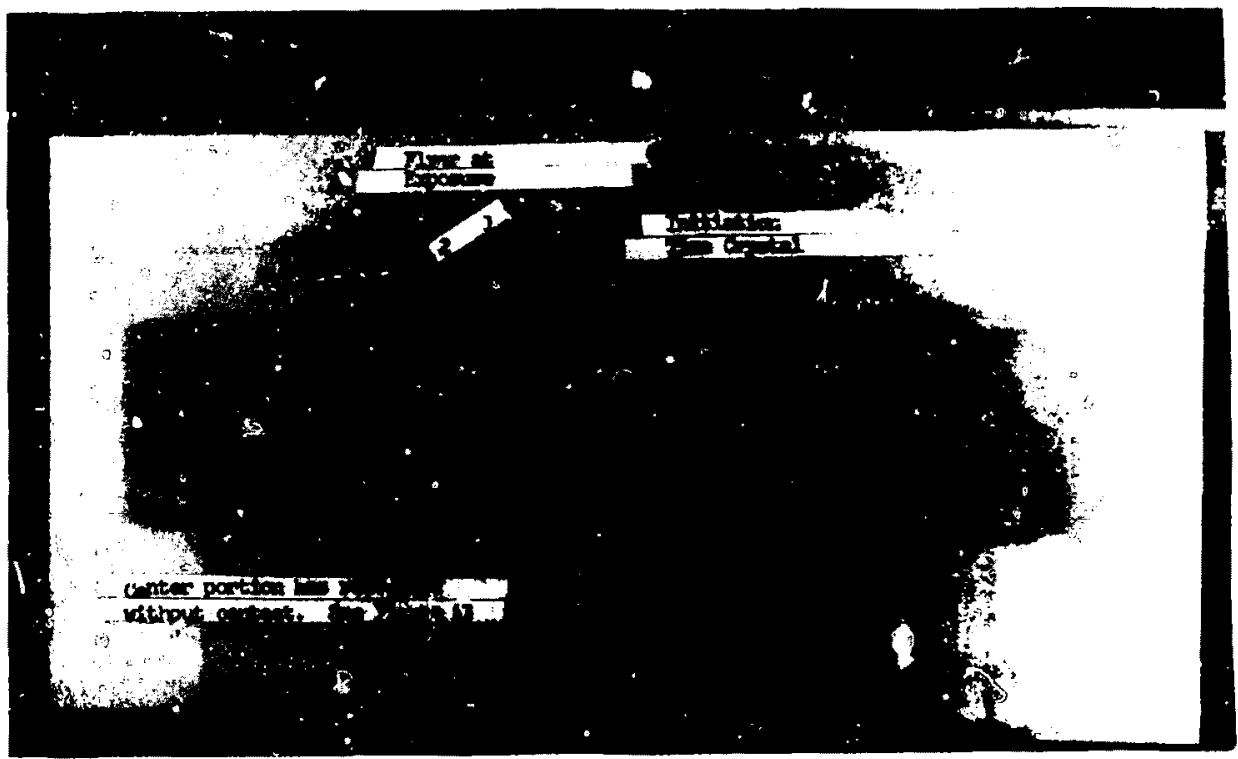





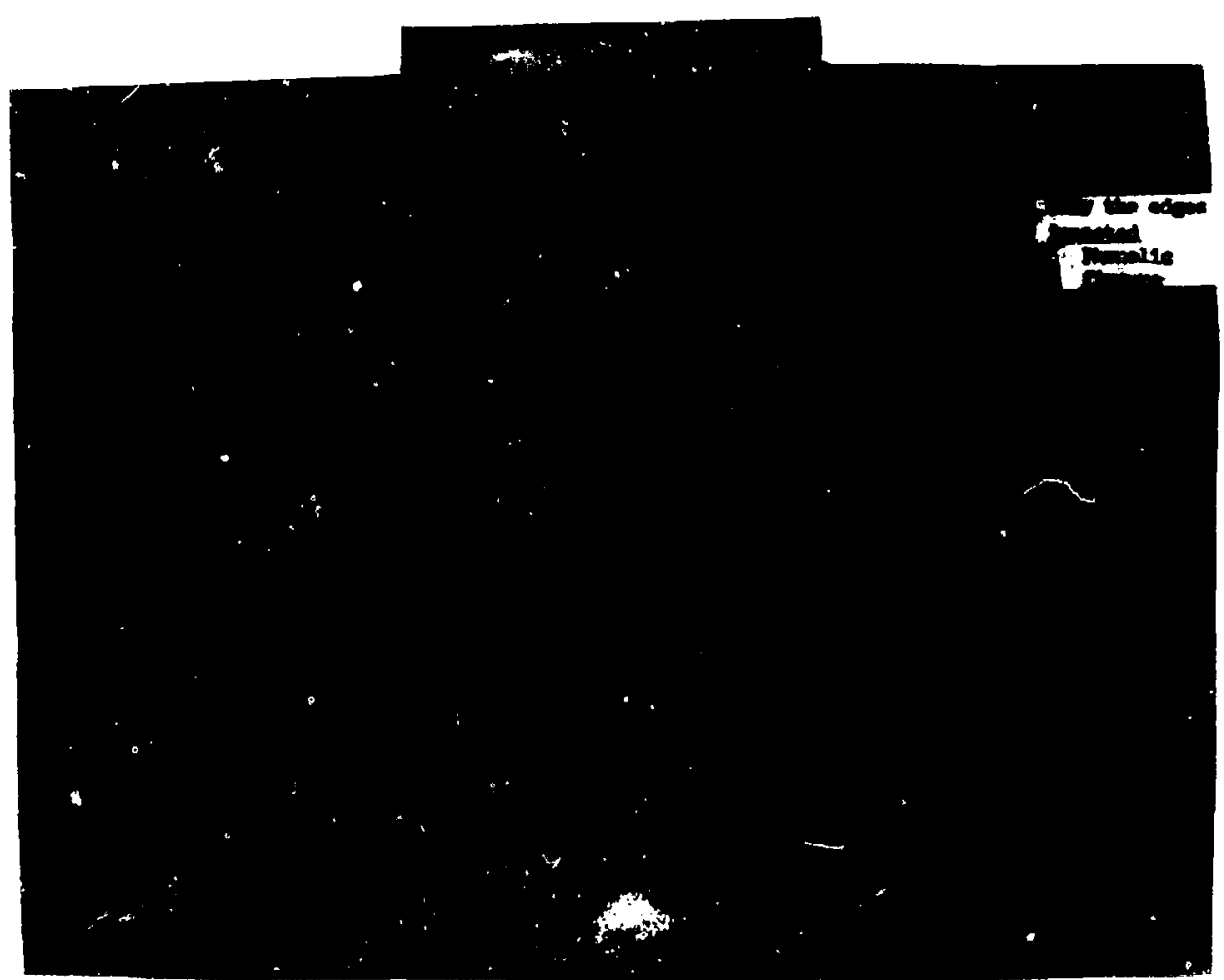




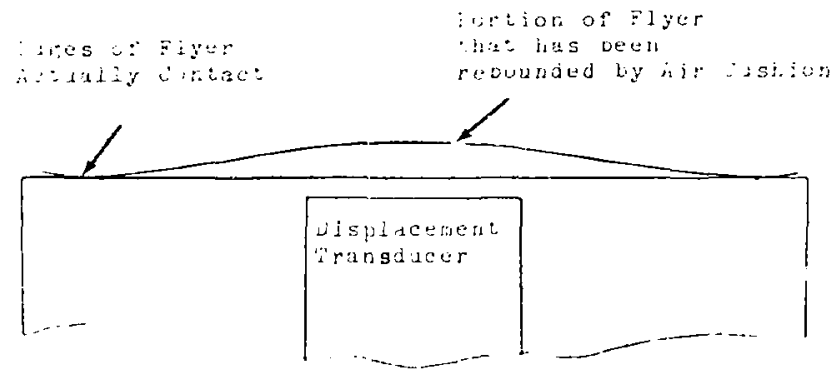

FIGURE 13. PROFILE OF FLYER PLATE AFTER CUSHION EFFECT HAS CAUSED REBOUND 


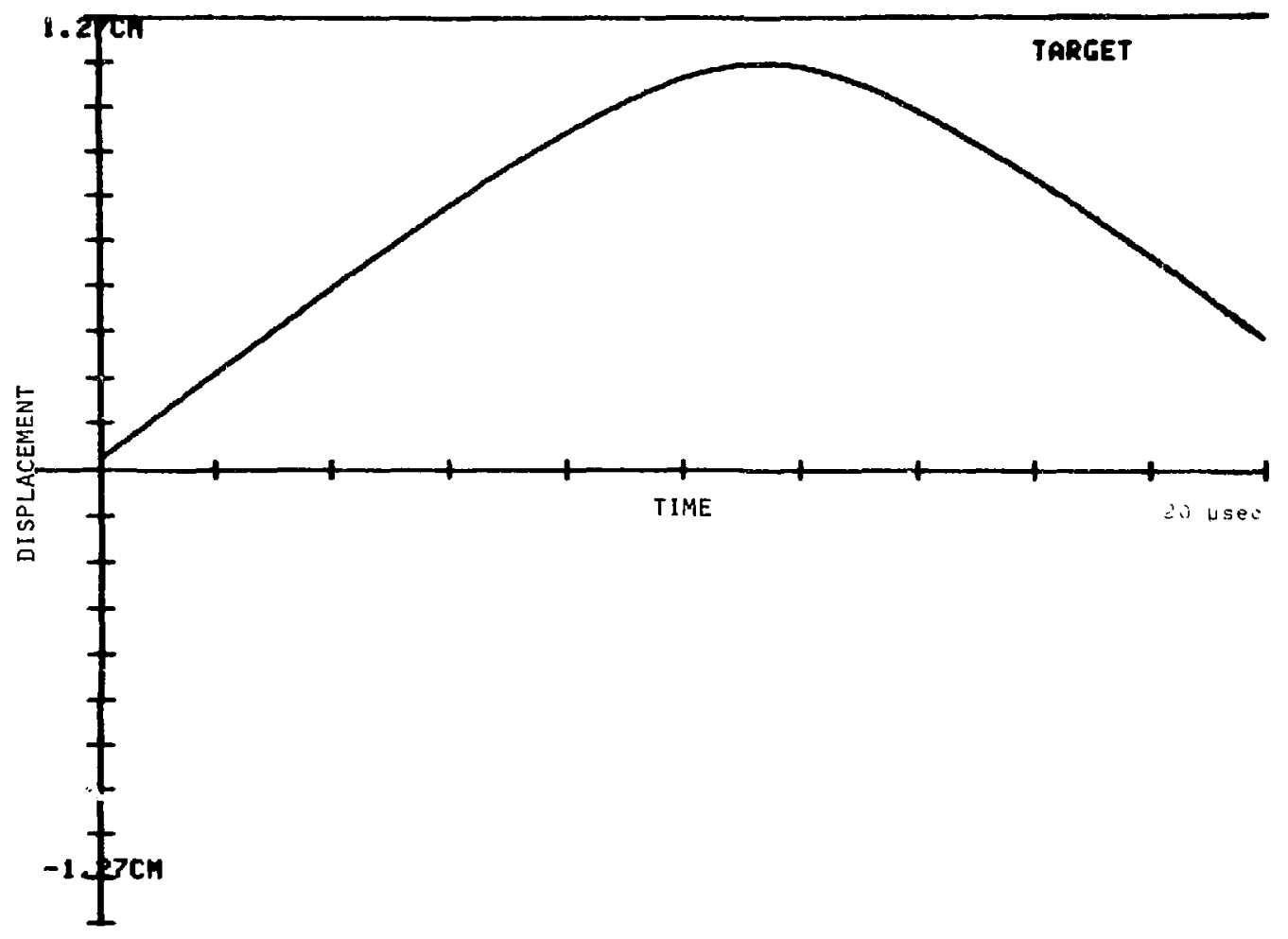




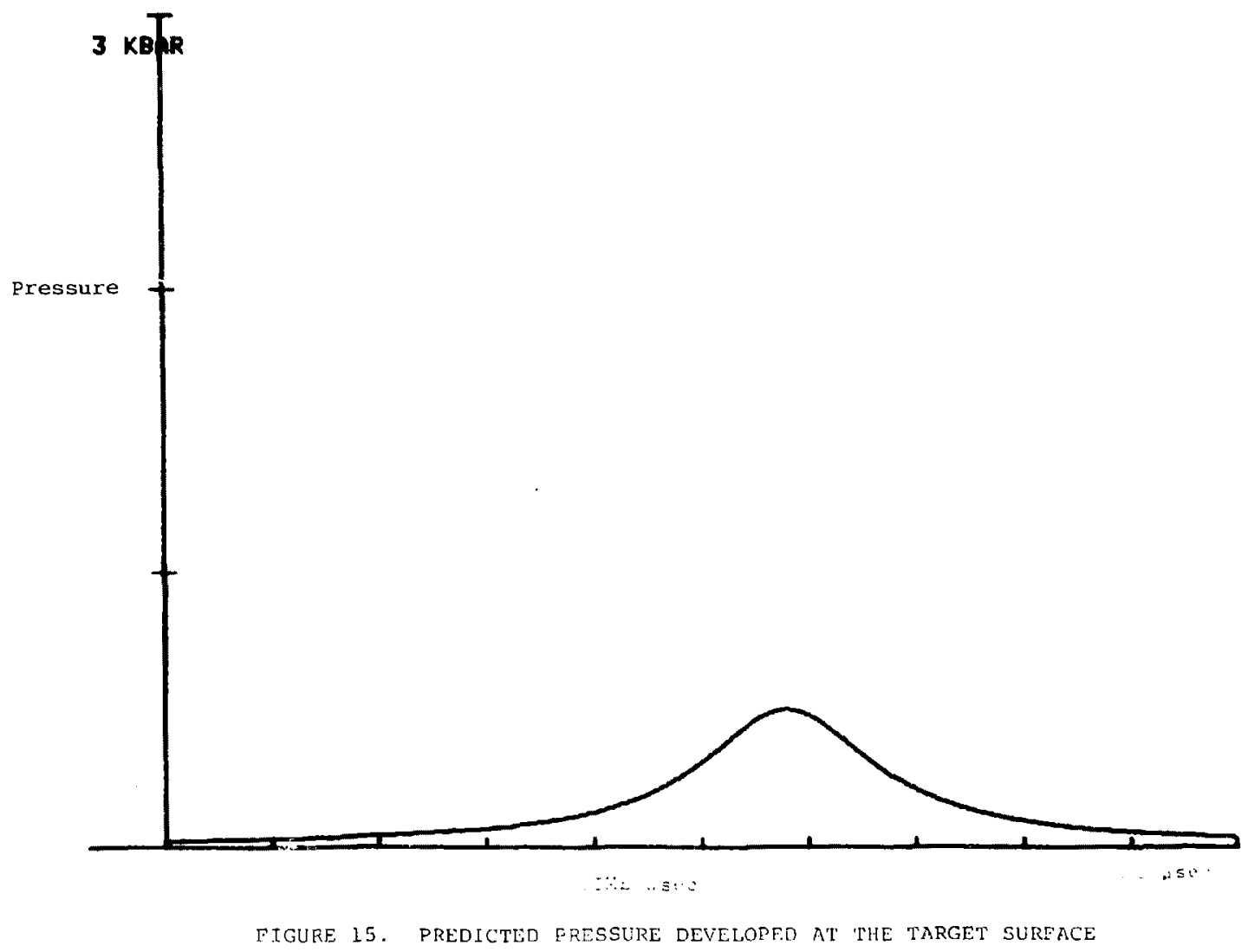


